\title{
Transferência de Tecnologia, Patentes e Inovação na Universidade Federal do Tocantins: um Estudo de Caso
}

\section{Transfer of Technology, Patents and Innovation at the Federal University of Tocantins: a Case Study}

\author{
Marco Antônio Baleeiro Alves ${ }^{1}$ \\ Gabriel Machado Santos ${ }^{1}$ \\ Marcos Antônio Dozza ${ }^{1}$ \\ Francisco Gilson Rebouças Pôrto Júnior ${ }^{1}$ \\ ${ }^{1}$ Universidade Federal do Tocantins, Palmas, TO, Brasil
}

\begin{abstract}
Resumo
A Universidade Federal do Tocantins (UFT) trabalha no depósito de patentes desde 2011, com a criação do seu Núcleo de Inovação Tecnológica (NIT). Em 2018, após criar seu portfólio de patentes, passou a ter como desafio a fase de Transferência de Tecnologia (TT). Percebeu-se então que seria preciso analisar todas as condições internas e externas à instituição acadêmica, considerando os pontos fracos e os pontos fortes. O objetivo deste trabalho é propor ações estratégicas que favoreçam a TT. Para tanto, utilizou-se como metodologias de pesquisa a exploratória, a explicativa, a descritiva e a bibliográfica, que contemplam, além do levantamento bibliográfico e da pesquisa no banco de dados de patentes do Instituto Nacional da Propriedade Industrial (INPI), uma visita técnica ao NIT da UFT, onde foi possível descrever a estrutura física e normativa disponível e os trâmites burocráticos e a predisposição deles para as novas ações estratégicas. As principais conclusões identificaram que é necessário implementar melhorias com vistas a promover o incentivo ao desenvolvimento $e$ a concepção de novas tecnologias mais adequadas para as necessidades do mercado, melhorar o sistema de redação de patentes, aperfeiçoar o processo de depósito de patentes, incrementar e apoiar ações caracterizadas no que se refere às atividades ligadas a um modelo mais próximo do que seria uma Agência de Inovação e Difusão Tecnológica e, finalmente, aventou-se a necessidade da construção de um planejamento estratégico mais robusto para favorecer a Transferência de Tecnologia.
\end{abstract}

Palavras-chave: Transferência Tecnológica. Tocantins. Patente. Inovação.

\begin{abstract}
The Federal University of Tocantins (UFT) has been working in patent filing since 2011, with the creation of its Office of Technological Innovation (OTI). In 2018, after creating its patent portfolio, it was challenged by the Technology Transfer (TT) phase. It was then realized that it would be necessary to analyze all the internal and external conditions of the academic institution, considering the weaknesses and strengths. Thus, the objective of this paper would be to propose strategic actions that favored TT. Therefore, we used an exploratory, explanatory, descriptive and bibliographic research methodology that included, besides the bibliographic survey and the research in the patent database of INPI (National Institute of Industrial Property), a technical visit to the UFT OTI where It was possible to describe the available physical and normative structure, the bureaucratic procedures and its predisposition to new strategic actions. The main conclusions were that improvements would need to be made to encourage the development and design of new technologies more suited to market needs, improve the patent drafting system, improve the patent filing process, step up and support actions. characterized with regard to activities related to a model closer to what would be a Technology Innovation and Dissemination Agency and, finally, the need for the construction of a more robust strategic planning aiming at favoring Technology Transfer.
\end{abstract}

Keywords: Technological Transfer. Tocantins. Patent. Innovation.

Área Tecnológica: Inovação. Gestão. 


\section{Introdução}

De acordo com os schumpterianos, a função da patente seria a de garantir a geração de recursos financeiros por meio da inserção desta no mercado. Sendo assim, no pensamento de Schumpeter (1997), a inovação precisaria de uma proteção e, somente assim, produziria desenvolvimento, logo, não existe concorrência perfeita, e sim o que seria, na sua visão, monopólios temporários (patentes) que substituem a tecnologia antiga por uma nova. Isto é, primeiramente ocorre a fase preliminar de destruição de uma velha tecnologia, por força da lei de mercado, $e$, em seguida, tem-se um processo de criação, desenvolvimento e comercialização. Por isso, é essencial a figura do empreendedor, que seria o promotor da inovação em vias de fato. Nesse contexto, acredita-se que o diagnóstico sobre o portfólio de depósitos de patentes de uma universidade pode ser importante para a verificação do potencial inovador da instituição em um dado contexto social e econômico. Para que ocorra o empreendedorismo com inovação, a iniciativa privada deve exercer papel preponderante para que o ciclo econômico esteja completo, mas, antes disso, será indispensável que o pesquisador, na condição de inventor, vença o desafio de produzir algo novo ou significativamente melhorado e, a princípio, este seria o fator preponderante que dariam condições mais vantajosas para a introdução destes ativos no mercado.

Observou-se que alguns autores trouxeram contribuições para a elucidação dos mecanismos de efetivação da Transferência de Tecnologia (TT) mas, para isso partiram de conceitos bem estabelecidos, os quais são usados no presente artigo. Podemos citar Bozeman (2000, p. 62), que define a TT como "[...] a transferência contratual de conhecimento tecnológico previamente apropriado por meio de mecanismos legais e de fomento, de uma organização para outra [...]". Esse conceito é um pouco diferente da visão de Stevens, Toneguzzo e Bostrom (2005, p. 9), que definem a TT como "[...] o conjunto de etapas que descrevem a transferência formal de invenções resultantes das pesquisas científicas realizadas pelas universidades ao setor produtivo". Entretanto, ambos os conceitos satisfazem os objetivos do presente estudo.

No Brasil, as Instituições de Ensino Superior (IES) têm sido cruciais na missão de produzir ciência, pesquisa e tecnologia, em consonância com as necessidades do mercado. Dessa forma, a comunidade universitária seria capaz de se preparar para as mudanças sociais que a tecnologia traz consigo a exemplo das exigências da chamada: "quarta revolução industrial" ou "era digital". Para atender a essa nova realidade, as instituições começam a ser desafiadas a mudar suas estruturas tradicionais e a buscar novas estratégias que lhes permitam gerar tecnologias úteis (DE BENEDICTO, 2011).

A Lei n. 13.243, de 11 de janeiro de 2016, em seu artigo $1^{\circ}$, altera a Lei n. 10.973, de 2 de dezembro de 2004, e estabelece 15 princípios dos quais pode-se destacar: "VIII - incentivo à constituição de ambientes favoráveis à inovação e às atividades de Transferência de Tecnologia". Nesse sentido, a necessidade de se conceber uma postura mais inovadora, a partir da nova missão atribuída às universidades, demonstra que essas instituições possuem uma importância fundamental para o processo de aceleração do desenvolvimento econômico de um país (AUDY; MOROSINI, 2007).

Como bem destacam Carvalho et al. (2017), ao afirmarem que a aproximação público/ privado somente terá êxito se houver simplificação dos processos administrativos de recursos humanos e financeiros nas universidades e descentralização do fomento ao desenvolvimento de setores de Ciência Tecnologia e Inovação nos Estados e Municípios, entende-se que tais 
condições precisariam de regulamentação adequada nas universidades e também por decretos e leis estaduais e municipais, algo ainda por fazer em algumas regióes do Brasil. Ainda segundo Carvalho et al. (2017), a aproximação da universidade com a iniciativa privada deverá ser apoiada pela "cultura empreendedora", que somente poderá ser desenvolvida por meio de "educação empreendedora", efetivamente inserida no currículo acadêmico.

Tendo por base a realidade burocrática das instituições públicas, entende-se que seria necessário praticar mudanças profundas na cultura organizacional, para que se torne empreendedora de fato e com efetiva regulamentação da relação público/privado. Assim, resoluções internas que propiciem a formalização dos NITs, bolsas de estímulo à atividade inovativa, apoio à $\mathrm{P} \& \mathrm{D}$ e incorporação desses temas na formação dos estudantes se fazem necessárias para a ação empreendedora. Reis e Gomes (2017) também fazem contribuições nesse sentido ao destacarem a importância do capital humano para a inovação.

Os processos de TT dependem fundamentalmente de capital humano de alta eficiência, e deveriam passar inicialmente pela apropriação do conhecimento tecnológico, o que requer recursos humanos de alta eficiência. Nesse contexto, tratam-se de processos complexos em que o vetor fundamental da dinâmica econômica passaria a depender da qualificação dos recursos humanos tendo em vista o favorecimento das relações entre os atores sociais (universidade, governo e indústria), aos quais deveriam possuir a competência em gerar sustentavelmente o processo de inovação e de distribuir os benefícios econômicos de forma socialmente justa $e$ economicamente correta (REIS; GOMES, 2017).

Kannebley Júnior, Shimada e De Negri (2016) chamam a atenção para a criação de um ambiente favorável à propriedade intelectual, com a efetiva proteção das patentes como mecanismo indutor de empreendedorismo e geração de desenvolvimento econômico, consequentemente, acredita-se que novos negócios em atividades locais também possam ser estimulados com isso. A exemplo das nações mais avançadas, quando se observa o nível de conhecimento tecnológico acumulado, ocorre indução natural da geração de inovações e incremento da produção econômica. Segundo Gonçalves, Ribeiro e Freguglia (2016), esse seria um dos motivos que contribuem para a desigualdade entre as nações avançadas e em desenvolvimento.

O Brasil, além de ocupar posição secundária no campo do desenvolvimento científico, possui uma base produtiva industrial com pouca intensidade em inovação. Assim ocorre, especialmente nos estados da Região Norte, na qual se destaca o caso do Estado do Tocantins já que os dispêndios em CT\&I são baixíssimos quando comparados a outros estados, além disso, existe baixo nível de crescimento industrial e tímida atuação de Fundações de Apoio, por outro lado, a tecnologia gerada e protegida na forma de patentes é de baixa densidade tecnológica.

Santos e Solleiro (2006) entendem que o processo de TT passa por diversas fases indispensáveis, as quais se iniciam no comunicado de invenção, que seria reportado ao NIT, em seguida, o processo de patente, o licenciamento, o uso comercial da tecnologia licenciada, e por fim os royalties. Sabe-se ainda que a qualidade das patentes tem sido um tema cada vez mais relevante na medida em que as universidades brasileiras desenvolvem suas políticas internas de inovação. Sendo assim, este trabalho tem como objetivo avaliar como pequenas ações institucionais ligadas ao NIT da UFT podem promover a melhoria de processos de TT. Tais ações podem ser: frequência de depósito de patentes, procedimento empregado para a redação das patentes, testes preliminares com o objetivo de verificar a patenteabilidade de novas tecnologias, além da importante busca de anterioridades, todos os processos de gestão 
de tecnológica, ações estratégicas no que se refere a estrutura física e normativa, os trâmites burocráticos e a predisposição para novas ações estratégicas para favorecer a TT aplicada ao portfólio de patentes da universidade. Nesse contexto, justifica-se o presente estudo tendo em vista a fase incipiente das ações de TT por parte da Universidade Federal do Tocantins e por meio de seu Núcleo de Inovação Tecnológica que ainda carece de aperfeiçoar sua estrutura física, de recursos humanos, processos normativos e planejamento estratégico consistente, além disso, o número de depósitos de patentes possui tendência de aumento e esse processo carece de gestão tecnológica constante.

\section{Metodologia}

A metodologia utilizada neste trabalho pode ser descrita basicamente em quatro fases de pesquisa: exploratória, explicativa, descritiva e bibliográfica. O período da pesquisa foi escolhido tendo em vista a criação do NIT da UFT em 2011 por meio da Resolução do Conselho de Ensino, Pesquisa e Extensão (CONSEPE) n. 02/2011 até o ano de 2018. As principais informações para embasar este trabalho foram levantadas por meio de coleta de dados, com pesquisas no sítio do Instituto Nacional da Propriedade Industrial (INPI), em pesquisa no número do Cadastro Nacional da Pessoa Jurídica (CNPJ), referente aos depósitos de patentes da universidade, desde suas primeiras ações em 2011 até 2018; entre outras fontes devidamente citadas.

A pesquisa exploratória teve como finalidade levantar informações sobre quais fatores seriam mais importantes para o favorecimento dos processos de Transferência de Tecnologia, patentes e inovação na Universidade Federal do Tocantins e quais seriam as suas delimitações, a tal ponto de obter-se um certo mapeamento para as condições de manifestação deste assunto.

A pesquisa exploratória foi a preparação para a pesquisa explicativa, um estudo preliminar do principal objetivo da pesquisa que deveria ser realizada, de acordo com Severino (2010). Esse processo soma-se ao método de pesquisa explicativa, pois além de registrar suas causas, analisa através de métodos matemáticos o comportamento do objeto estudado (SEVERINO, 2010).

Com base na visão de Prondanov e Freitas (2013), a pesquisa descritiva realizada neste trabalho, se traduz na descrição dos fatos observados e das características das ações da UFT, sempre em consonância com os dados fornecidos pelo INPI e pelas referências consultadas.

$\mathrm{Na}$ abordagem descritiva, foi realizado um histórico, e um diagnóstico das circunstâncias atuais com a finalidade de trazer um melhor esclarecimento sobre o papel que os depósitos de patentes poderiam oferecer para o tema em estudo.

Nas fases descritiva e bibliográfica, pautou-se principalmente pela coleta de dados e observação direta, tendo em vista o reduzido tamanho do objeto de estudo, pois a equipe do NIT é pequena e o número de depósitos de patentes ainda é incipiente.

\section{Resultados e Discussões}

Desde a criação da Lei de Inovação (Lei n. 10.973/2004), intensificou-se o fenômeno caracterizado por iniciativas por parte dos docentes, estudantes e técnicos das universidades 
públicas em todo o país, no sentido de colocar em prática experiências criativas de incubadoras de empresas para o desenvolvimento de startups, com menor custo possível. Apesar dos efeitos da grande crise econômica mundial, desencadeada a partir de 2008 nos EUA, nos anos de 2004 a 2012, o Brasil assistiu a um crescimento considerável nesse sentido.

A exemplo de outras experiências, e sempre com parcerias estratégicas do sistema S, mesmo com poucos recursos financeiros e valendo-se de uma infraestrutura preexistente, a Universidade Federal do Tocantins tem desenvolvido ações importantes, no entanto ainda em estado incipiente de desenvolvimento que ao todo são 4 iniciativas, as quais são elencadas na Tabela 1 a seguir:

Tabela 1 - Relação das incubadoras da UFT, seus objetivos e data de criação

\begin{tabular}{|c|c|c|}
\hline Nome & OвJETIVOS & $\begin{array}{l}\text { ANO DE } \\
\text { CRIAÇÃO }\end{array}$ \\
\hline $\begin{array}{l}\text { Incubadora } \\
\text { de Empresas } \\
\text { da UFT }{ }^{1}\end{array}$ & $\begin{array}{l}\text { "Incentivar e apoiar a criação e o desenvolvimento de empresas de base tecnológica } \\
\text { por meio do provimento de infraestrutura básica compartilhada, de mecanismos } \\
\text { de apoio à inovação e cooperação tecnológica, de qualificação técnica e gerencial } \\
\text { do empreendedor e de orientação administrativa e gerencial". }{ }^{1}\end{array}$ & $2015^{1}$ \\
\hline $\begin{array}{l}\text { Incubadora } \\
\text { HABITE Gurupi }\end{array}$ & $\begin{array}{l}\text { "auxiliar no desenvolvimento e na consolidação de empreendimentos oriundos de } \\
\text { projetos de pesquisa e extensão desenvolvidos no âmbito acadêmico, bem como na } \\
\text { comunidade em geral; Levar as empresas a atingirem um grau de amadurecimento } \\
\text { que viabilize sua sustentabilidade e crescimento fora do ambiente da Incubadora; } \\
\text { Dar suporte às empresas vinculadas ao Programa de Incubação, com o intuito de } \\
\text { capacitá-las para que atinjam o sucesso; Promover o estabelecimento de parcerias } \\
\text { e redes de relacionamento que agreguem valor competitivo ao negócio". }\end{array}$ & $2014^{2}$ \\
\hline $\begin{array}{c}\text { Incubadora } \\
\text { de Projetos } \\
\text { Pedagógicos } \\
\text { e Inovação } \\
\text { para Escolas } \\
\text { de Ensino } \\
\text { Fundamental } \\
\text { e Médio }\end{array}$ & $\begin{array}{l}\text { "Aproximar a comunidade acadêmica de cursos da UFT e pesquisadores do } \\
\text { Grupo de Pesquisa e Núcleo de Pesquisa e Extensão Observatório de Pesquisas } \\
\text { Aplicadas ao Jornalismo e ao Ensino (OPAJE, UFT) das escolas públicas e da } \\
\text { comunidade tradicionais, com foco na transferência de expertise, visando a } \\
\text { publicização e popularização do que é desenvolvido pela ciência. Além disso, } \\
\text { o projeto visa proporcionar o empoderamento de professores e alunos para o } \\
\text { acesso e a apropriação comunitária de tecnologias sociais e bens informacionais } \\
\text { que os habilitem a desenvolver projetos pedagógicos e de inovação em suas } \\
\text { comunidades".3 }\end{array}$ & $2015^{3}$ \\
\hline $\begin{array}{l}\text { Incubadora } \\
\text { Social de } \\
\text { Empresas } \\
\text { da UFT }\end{array}$ & $\begin{array}{l}\text { "Prestar apoio a empreendimentos nas áreas de agropecuária, serviços, comércio, } \\
\text { indústria e terceiro setor, contribuindo assim para o desenvolvimento local } \\
\text { sustentável e a capacitação e especialização dos envolvidos". } 4\end{array}$ & $2014^{4}$ \\
\hline
\end{tabular}

Fonte: ${ }^{1}$ UFT (2018); ${ }^{2}$ UFT (2016); ${ }^{3 P R O E X ~ U F T ~(2018) ; ~}{ }^{4}$ UFT (2014)

De acordo com a observação direta e os dados disponíveis na PROEX UFT (2018), observou-se que a Incubadora de Empresas da UFT já acumula algumas experiências importantes e já incubou algumas propostas de empresas nascentes desde a sua criação, no entanto nenhuma empresa conseguiu se adaptar ao mercado após o período de incubação.

A incubadora HABITE Gurupi, teve seu prédio inaugurado em 2014 e seu primeiro edital foi publicado em 2016, possui uma área tecnológica mais restrita pois o interessado deve configurar-se como Empresa de Biotecnologia, nas áreas de interesse da Incubadora, prioritariamente sendo: Agronegócio; Biotecnologia; Gestão Ambiental e Tecnologia da Informação. Já a Incubadora de Projetos Pedagógicos e Inovação para as Escolas de Ensino Fundamental e Médio procura direcionar seu foco em transferência de expertise a professores e alunos de 
escolas públicas. Em outro caso, a Incubadora Social de Empresas da UFT ainda está em fase muito incipiente de desenvolvimento e possui apenas 1 edital publicado.

Neste estudo, observou-se que existem interessantes iniciativas de construção e execução de projetos de Incubadoras na Universidade Federal do Tocantins, especialmente nos campi universitários das cidades de Palmas e Gurupi, no entanto, até o momento nenhum dos 32 depósitos de patentes foram objetos de transferência de tecnologia em nenhuma das incubadoras mencionadas.

Sabe-se há muito tempo que, segundo alguns especialistas no tema, como Harbison (1963), o fator determinante para o atraso econômico dos países menos desenvolvido, além da pobreza, seria a escassez de recursos humanos disponíveis, uma vez que, persiste uma situação de baixa intensidade de qualificação, e ainda, para Teixeira (2007) a escassez de capital humano qualificado é fator que tem implicações negativas sobre a P\&D, isto é, limita a capacidade de introduzir melhorias na qualidade dos bens e serviços, e, consequentemente, restringe o progresso material e tecnológico de uma dada região. Bresser-Pereira (2008) reforça essa linha de raciocínio ao afirmar que, investimentos em capital humano poderiam gerar ganhos de competitividade e de crescimento econômico para a sociedade no contexto da CT\&I.

Tendo em vista a importância da qualificação de recursos humanos para a pesquisa e inovação, no Boletim Interno n. 118 de 22 de setembro de 2015 (Portaria n. 1.584, de 21/09/2015), o então Reitor da UFT nomeou uma comissão especial responsável pela organização e implantação do Mestrado em Transferência de Tecnologia e Propriedade Intelectual (PROFNIT) implementado em rede e em mais de 16 polos por uma louvável iniciativa do Fórum Nacional de Gestores FORTEC em rede nacional de Pontos Focais, com sede acadêmica em cada um dos pontos focais e oferecido aos profissionais graduados que atuam em Propriedade Intelectual, Transferência de Tecnologia e Inovação Tecnológica dentro do âmbito das competências dos Núcleos de Inovação Tecnológica (NITs), servidores e membros de equipes de Instituições de Ciência e Tecnologia (ICTs), bem como em outras instâncias afins do Sistema Nacional de Ciência, Tecnologia e Inovação (SNCTI) (PROFNIT, 2018).

De acordo com a pesquisa realizada, 17 (dezessete) depósitos de patentes já foram publicados e 13 (treze) estão sob sigilo, 1 (uma) anulado e 1 (uma) indeferido. São considerados depósitos de patentes em sigilo aquelas que não foram publicadas, isto é, não está disponibilizada no site do INPI para consulta. O indeferimento do depósito de patente ocorreu por não apresentar recurso dentro do prazo legal.

Para salientar a importância da TT, é interessante que o NIT da UFT tivesse um sistema de monitoramento dos depósitos das patentes mais especializado ou realizado por uma empresa terceirizada e especializada para evitar possíveis problemas nas ações corretivas, no tempo previsto em lei, evitando anulação e indeferimento dos processos de depósito de patente.

Identificou-se com esta pesquisa que apenas um servidor do NIT faz esse acompanhamento semanal por meio da consulta à Revista da Propriedade Industrial por meio da Resolução n. 22/2013, de 18 de março de 2013, publicada todas as terças-feiras no site do INPI (http:// revistas.inpi.gov.br/rpi/). Além disso, a Universidade Federal do Tocantins não conta com um servidor devidamente treinado e qualificado para dar respaldo às redações de patentes requeridas pelos pesquisadores, de forma que os próprios inventores fazem esse trabalho. Isso requer um pouco mais de tempo e pode gerar insegurança, por parte da iniciativa privada, no que se refere à suficiência descritiva. 
Estudos de Lucena e Sproeser (2015) e Dias e Porto (2013) observaram que quando a redação das patentes é realizada por equipe especializada do NIT ou é terceirizada para uma empresa de consultoria em Propriedade Intelectual e Redação de Patentes, o processo de Transferência de Tecnologia é facilitado. Outros pontos foram considerados, por exemplo, o número reduzido de pessoas que trabalham no NIT da UFT. Atualmente, esse dispõe de apenas um profissional docente a qual exerce o cargo diretora, um servidor técnico administrativo em educação (TAE) e dois estagiários estudantes de graduação da universidade.

No caso de estagiários o fator desfavorável mais importante seria a rotatividade e a experiência pouco considerável em TT. De acordo com Rosa \& Frega (2017) esse ponto é percebido como uma questão negativa por diversos estudos sobre Núcleos de Inovação.

Outro fator a ser considerado relevante é que o Núcleo de Inovação Tecnológica da UFT é vinculado à Pró-reitoria de Pesquisa, Pós-Graduação e Inovação (PROPESQI), de acordo com Kaymaz e Eryiğit (2011), a autonomia é um fator facilitador pois melhora o fluxo de informação e o alinhamento de incentivos e reduz a dependência de processos burocráticos inerentes aos procedimentos internos de uma instituição pública. Além disso, acredita-se que um Núcleo de Inovação autônomo com um CNPJ próprio poderia até mesmo administrar recursos financeiros e agilizar o fluxo de atividades em função das necessidades da universidade e dos pesquisadores, estudantes, discentes, professores e inventores e até mesmo melhorar a relação universidade-empresa.

O Gráfico 1, mostra a evolução dos depósitos de patentes em números absolutos nos anos de 2013 a 2018, que na média foi aproximadamente 5 depósitos por ano. Segundo informações do NIT UFT, em 2010 não houve nenhum depósito de patente, porém entre 2011 e 2012 houveram apenas dois depósitos de patentes, sendo que em 2013 havia um terceiro processo de depósito em andamento.

A partir de 2014 passou a existir uma maior celeridade nos processos de depósitos de patentes pois houve um acúmulo de experiência e de entendimento da Procuradoria Federal da UFT, bem como os trâmites internos do NIT e da PROPESQI passaram a ter um fluxo mais conhecido, o que acarretou maior agilidade nas tramitações, tanto no processo de comunicação da invenção por parte dos pesquisadores remetida ao NIT, quanto no que se refere as fases do pagamento da GRU (Guia de Recolhimento da União), emitida pelo INPI e paga por meio de nota de empenho emitida pela PROAD (Pró-reitoria de Administração e Finanças da UFT).

Por todas estas afirmações, acredita-se que a experiência acumulada das pessoas envolvidas nos processos administrativos, contribuiu para o favorecimento dos processos de Transferência de Tecnologia da Universidade, uma vez que esse fator está ligado ao conhecimento tácito da instituição, mesmo que ainda não tenha tido resultados numéricos concretos no que se refere a licenciamentos. Portanto, a Gráfico 1 mostra o quantitativo dos depósitos de patente da UFT entre os anos 2013 a 2018: 
Gráfico 1 - Evolução dos Depósitos de Patentes da UFT de 2013 a 2018

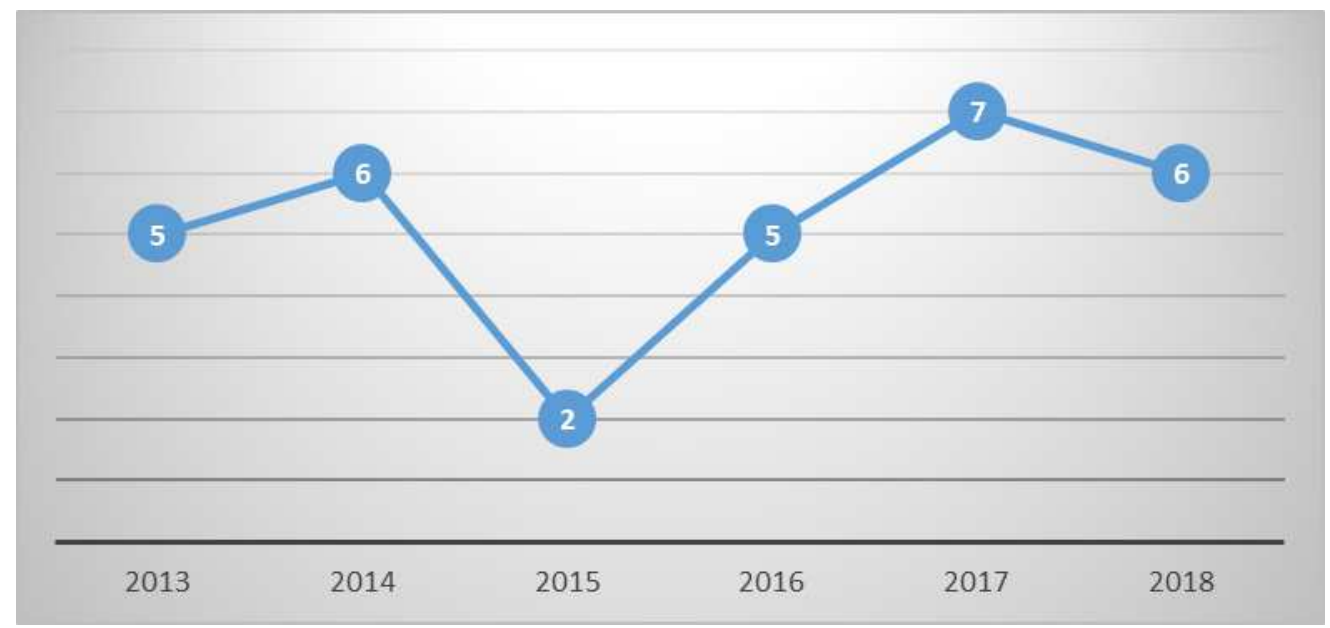

Fonte: Adaptado do INPI (2018)

Portanto, a taxa de crescimento com relação ao ano anterior, no ano de 2014 , teve um aumento de $20 \%$. No ano de 2015 , houve uma queda brusca diminuindo em $66,67 \%$, a recuperação se deu nos dois anos subsequentes (2016 e 2017), que aumentaram respectivamente em $150 \%$ e 40\%. Em 2018 voltou a ter uma queda de 14,29\%.

O perfil dos depósitos de patentes da UFT contém 13\% sob a forma de Modelo de Utilidade (MU) e $87 \%$ do tipo Patente de Invenção (PI). Esse perfil mostra claramente que a produção de patentes da UFT está voltada para PI, sendo que MU corresponde a um percentual muito pequeno. Diferente com o que corre com o estado do Tocantins que tem outro perfil, em que, $44 \%$ são MU e $56 \%$ corresponde a PI. O que difere do perfil da UFT onde sua produção é 80\% maior em PI. Esses dados podem indicar um certo potencial para geração de inovações disruptivas da UFT e do estado do Tocantins devido aos maiores números de depósitos de PI em função do menor número de depósitos de patentes de MU. A seguir a Tabela 2 evidencia os depósitos de patentes por estado do Brasil.

No que se refere aos depósitos de patentes residentes no Brasil, os estados que mais depositam patentes são: São Paulo (SP), Rio de Janeiro (RJ) e Minas Gerais (MG), que juntos correspondem a 53,8\% dos depósitos de patentes de universidades do país, dessa forma, mais da metade dos depósitos estão concentrados na região Sudeste. Isso pode ser explicado pelo número de indústrias que a região possui, maior poder econômico, maior população, bem como maiores investimentos em pesquisa, ciência e tecnologia em relação ao restante do país. Consequentemente, este desenvolvimento econômico está frequentemente associado a uma melhor estrutura de qualificação de recursos humanos. O Tocantins fica em $23^{\circ}$ no ranking dos estados, quando analisados os números absolutos entre os anos de 2013 a 2017 em relação aos depósitos de PI, tendo uma melhor produção em 2017 com 14 depósitos e sua menor produção em 2015 com 4 depósitos.

A região Sudeste tem o maior número de PIs, com 14.502 depósitos com destaque para $\mathrm{SP}$, região que corresponde a $60,38 \%$ do total. O Tocantins fica em $22^{\circ}$ no ranking dos estados quando analisados em números absolutos os anos de 2013 a 2017 em relação aos depósitos de MU, tendo uma maior produção em 2013 e sua menor produção nos anos de 2014 e 2015. 
Tabela 2 - Depósitos de Patentes por Estado

\section{ESTADO}

Acre

Alagoas

Amazonas

Amapá

Bahia

Ceará

Distrito Federal

Espírito Santo

Goiás

Maranhão

Minas Gerais

Mato Grosso do Sul

Mato Grosso

Pará

Paraíba

Pernambuco

Piauí

Paraná

Rio de Janeiro

Rio Grande do Norte

Rondônia

Roraima

Rio Grande do Sul

Santa Catarina

Sergipe

São Paulo

Tocantins

\section{TOTAL}

29

199

200

10

836

690

451

852

707

219

3.928

279

214

207

428

838

127

3.548

3.349

317

83

19

3.835

2.777

234

14.010

78

Total

Fonte: INPI (2018)

Os Gráficos 2 e 3 mostram que em 2017 o Tocantins, estado mais novo do Brasil, representa um papel importante nos depósitos de patente na região Norte, uma vez que ficou como o terceiro colocado com o maior número de depósitos, tanto de Patente de Invenção (PI) como de Modelos de Utilidade (MU), ficando atrás apenas dos estados da Amazônia e do Pará. 
A região Sudeste tem o maior número de Modelos de Utilidade (MU) com 7.692 depósitos com destaque para SP que apresentou 14010 depósitos. Esses dados se devem ao fato de que a Região Sudeste possui muitas indústrias nacionais e internacionais muito competitivas no mercado, isso faz com que o investimento privado considere a propriedade industrial como sendo uma crescente prioridade.

Gráfico 2 - Depósitos de PI na Região Norte 2017

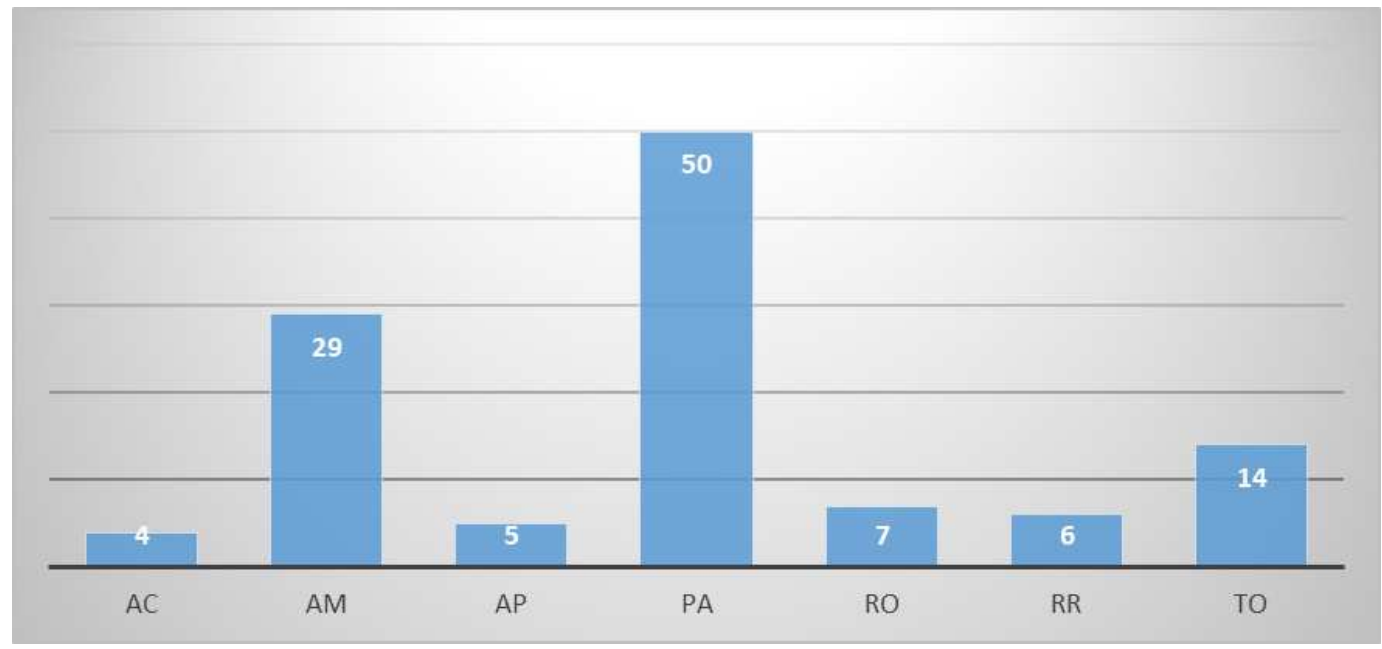

Fonte: INPI (2018)

Gráfico 3 - Depósitos de MU na Região Norte 2017

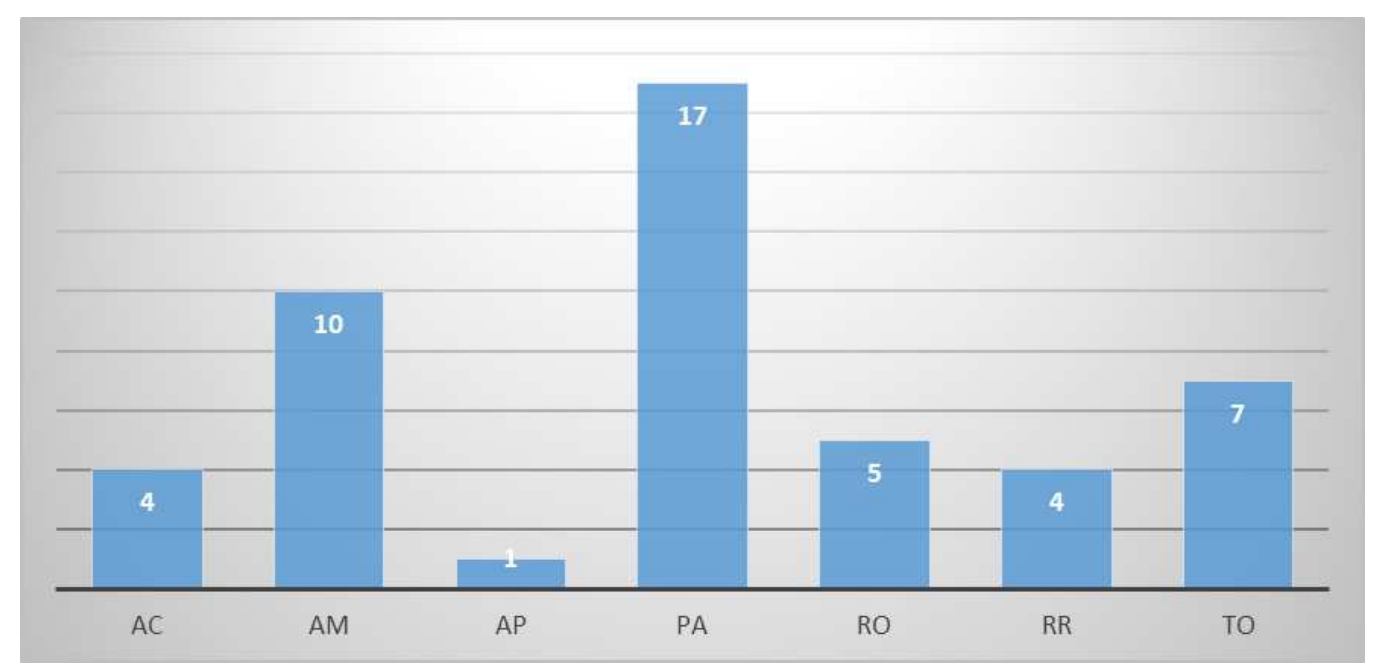

Fonte: Adaptado do INPI (2018)

Conforme mostra a Tabela 3, pode-se dividir os setores tecnológicos de depósitos em duas grandes áreas que dominam a produção de depósitos de patentes na UFT: área da "Química" e "Necessidades Humanas". Apenas um depósito se enquadra na área da "Construção Fixa". Apesar de serem constituídos por aspectos semelhantes, esses setores apresentaram depósitos de patentes caracterizados por atividades diversas as quais podem ser divididas basicamente em: "saúde", "química orgânica", "química inorgânica", "agricultura" e "produtos alimentícios".

De acordo com o Quadro 1 demonstrado a seguir, a indústria do Tocantins é concentrada nas áreas de extração de minerais não metálicos, alimentos e produtos de minerais não metáli- 
cos, já os depósitos de patentes da Universidade Federal do Tocantins se concentram em grande predominância nas áreas de alimentos, mineração, biodiversidade, bioquímica, biotecnologia e construção civil.

Quadro 1 - Total de empresas por setor e porte no Estado do Tocantins

\begin{tabular}{|c|c|c|c|c|c|c|}
\hline \multirow{3}{*}{ Setores (CNAE) } & \multirow{2}{*}{\multicolumn{2}{|c|}{ TOTAL }} & \multicolumn{4}{|c|}{ Porte } \\
\hline & & & \multicolumn{2}{|c|}{ Pequeno } & \multicolumn{2}{|c|}{ Médio/Grande } \\
\hline & N. & $\%$ & N. & $\%$ & N. & $\%$ \\
\hline Total & 65 & 100 & 45 & 100 & 20 & 100 \\
\hline Extração de minerais não metálicos & 6 & 9,2 & 5 & 11,11 & 1 & 5 \\
\hline Atividades de apoio a extração de minerais & 1 & 1,5 & 1 & 2,2 & 0 & 0 \\
\hline Alimentos & 17 & 26,2 & 8 & 17,8 & 9 & 45 \\
\hline Produtos Têxteis & 1 & 1,5 & 1 & 2,2 & 0 & 0 \\
\hline Vestuário e Acessórios & 3 & 4,6 & 3 & 6,7 & 0 & 0 \\
\hline Couros e artefatos de couro & 1 & 1,5 & 0 & 0 & 1 & 5 \\
\hline Produtos de madeira & 1 & 1,5 & 1 & 2,2 & 0 & 0 \\
\hline Impressão e reprodução de gravações & 1 & 1,5 & 1 & 2,2 & 0 & 0 \\
\hline $\begin{array}{c}\text { Químicos } \\
\text { (Exceto higiene pessoal, perfumaria e cosméticos) }\end{array}$ & 2 & 3,1 & 1 & 2,2 & 0 & 5 \\
\hline Produtos de borracha & 3 & 4,6 & 2 & 4,4 & 1 & 5 \\
\hline Produtos de minerais não metálicos & 22 & 33,8 & 15 & 33,3 & 1 & 35 \\
\hline Metalurgia & 1 & 1,5 & 1 & 2,2 & 7 & 0 \\
\hline Produtos de metal (exceto máquinas e equipamentos) & 3 & 4,6 & 3 & 6,7 & 0 & 0 \\
\hline Veículos automotores, reboques e carrocerias & 2 & 3,1 & 2 & 4,4 & 0 & 0 \\
\hline $\begin{array}{l}\text { Manutenção, reparação e instalação } \\
\text { de máquinas e equipamentos }\end{array}$ & 1 & 1,5 & 1 & 2,2 & 0 & 0 \\
\hline
\end{tabular}

Fonte: FIETO (2018)

Partindo-se do raciocínio de que a geração de "inovações tecnológicas" podem ser desenvolvidas a partir da identificação de "problemas" tecnológicos e que estes por sua vez seriam o ponto de partida para novas "soluções" tecnológicas, descobriu-se que ao cruzar as informações com dados da Federação das Indústrias do Estado do Tocantins (FIETO, 2018), percebeu-se que existe uma boa consonância das atividades de pesquisa em inovação tecnológica para produção de patentes na UFT, com o conjunto dos interesses das indústrias que se encontrariam atualmente instaladas no Estado do Tocantins.

Por outro lado, é interessante mencionar que, quando se consideram estes obstáculos como "problemas tecnológicos" reais que poderiam ser passíveis de soluções diversas por meio de inovações tecnológicas possivelmente propostas pela academia em futuro próximo, dos 15 obstáculos verificados ao desenvolvimento do setor industrial pela pesquisa FIETO (2018), apenas um se enquadra em algum dos setores tecnológicos identificados nos depósitos de patentes da UFT. 
Esses 15 obstáculos citados pela pesquisa da FIETO (2018) também foram pesquisados no restante do Brasil e apresentaram valores porcentuais próximos, são eles: Elevada carga tributária (TO: 36,92\%; BR: 49,05\%), falta ou alto custo de energia (TO: 35,38\%; BR: 18,93\%), Inadimplência dos clientes (TO: 20,31\%; BR: 16,90\%), competição desleal (TO: 29,69\%; BR: 17,81\%), demanda interna insuficiente (TO: 23,44\%; BR: 27,97\%), falta de capital de giro (TO: $21,54 \%$; BR: 21,38\%), alto custo da matéria prima (TO: 18,46\%; BR: 22,31\%), dificuldades na logística e no transporte (TO: 15,38\%; BR: 10,82\%), burocracia excessiva (TO: 13,85\%; BR: 14,41\%), alto custo do trabalhador qualificado (TO: 12,31\%; BR: 7,47\%), taxas de juros elevadas (TO: 20,77\%; BR: 18,5\%), insegurança jurídica (TO: 7,69\%; BR: 5,49\%), falta de financiamento de longo prazo(TO: 7,69\%; BR: 7,97\%), demanda externa insuficiente (TO: 4,62\%; BR: 9,74\%), competição com importados(TO: 3,08\%; BR: 6,37\%).

Conforme mostra a Tabela 3, observa-se que o depósito de patente BR10 2019002743 6 intitulado "GERADOR ELÉTRICO HÍBRIDO EÓLICO SOLAR COMBINADOS EM EIXO VERTICAL", cujo setor tecnológico seria na área de "Energias Renováveis" estaria consonante ao obstáculo "falta ou alto custo de energia" apontado pela FIETO (2018). Sendo assim, ainda é pouco expressiva a comunicação entre o corpo acadêmico da UFT, que produz inovação tecnológica de qualidade, com o conjunto de empresários e gestores da iniciativa privada que compõem a indústria tocantinense, o que faz com a universidade ainda não tenha realizado nenhuma transferência de tecnologia.

Tabela 3 - Campo Tecnológico das Patentes da UFT

\begin{tabular}{|c|c|}
\hline $\begin{array}{c}\text { Depósito DE } \\
\text { Patentes/Processo }\end{array}$ & Campo Tecnológico das Patentes \\
\hline BR10 20190027436 & Energias Renováveis \\
\hline BR10 20170073599 & Agroquímica \\
\hline BR 1020160147670 & Química Orgânica \\
\hline BR 1020160101530 & Produtos Alimentícios/Indústria Láctea \\
\hline BR 1020160088887 & Produtos Alimentícios/Óleos ou Gorduras \\
\hline BR 1020160069874 & Produtos Alimentícios/Separação de Proteínas \\
\hline BR 1020160050065 & Tratamento de Água/Química/Polímeros \\
\hline BR 1020150163568 & Construções Fixa/Edificação/Engenharias \\
\hline BR 1020140291954 & Química/Aparelhos/Enzimologia ou Microbiologia \\
\hline BR 1020140291946 & Química/Enchimento para Argamassas, Concreto ou Pedra Artificial \\
\hline BR 1020140263250 & $\begin{array}{c}\text { Produtos Alimentícios/Conservação ou Amadurecimento } \\
\text { Químico de Frutas ou Legumes Congelamento }\end{array}$ \\
\hline BR 1020140234470 & Produtos Alimentícios/Conservação de Alimentos ou Produtos Alimentícios, em Geral \\
\hline BR 1020140181881 & $\begin{array}{c}\text { Produtos Alimentícios/Obtenção de Composições à Base } \\
\text { de Proteínas para Produtos Alimentícios }\end{array}$ \\
\hline BR 1020140129715 & $\begin{array}{l}\text { Agricultura/Biocidas, Repelentes ou Atrativos de Pestes ou } \\
\text { Reguladores do Crescimento de Plantas Dispersões ou Géis }\end{array}$ \\
\hline BR 2020130340770 & $\begin{array}{l}\text { Saúde/Recipientes Especialmente Adaptados para Finalidades } \\
\text { Médicas ou Farmacêuticas Suportes para Recipientes }\end{array}$ \\
\hline BR 1020130207969 & $\begin{array}{c}\text { Química/Preparação de Polissacarídeos não Abrangidos } \\
\text { pelos Grupos Pectina e seus Derivados }\end{array}$ \\
\hline BR 2020130093217 & Saúde/Salvamento; Recreação/Instrumentos para Ausculta Estetoscópios Elétricos \\
\hline BR 1020130040959 & $\begin{array}{c}\text { Química/Compostos de Alumínio Compostos Duplos Contendo Tanto } \\
\text { Alumínio Como Metais Alcalinos ou Metais Alcalino Terrosos }\end{array}$ \\
\hline
\end{tabular}

Fonte: Adaptada de INPI (2018) e NIT-UFT (2018) 
Na Tabela 4, a Universidade com o maior número de depósitos de PI é a USP seguidos da UNICAMP e UFMG com respectivamente 311, 309, e 295 todas situadas na região Sudeste do país. Em ranking de 192 instituições federais, a UFT ficou na 55 quinta posição, considerada uma boa colocação, mas longe ainda de ficar entre as primeiras.

Tabela 4 - Ranking das Posições das Instituição Superiores do Brasil 2013-2017 dos depósitos de patentes

\begin{tabular}{|c|c|c|}
\hline Posição & $\begin{array}{c}\text { RANKING DAS POSIÇÕES DAS INSTITUIÇÃo SUPERIORES do BRASIL } 2013 \text { - } 2017 \text { dos } \\
\text { DEPósItos DE PI }\end{array}$ & QD \\
\hline $1^{\circ}$ & Universidade de São Paulo - USP & 311 \\
\hline $2^{\circ}$ & Universidade Estadual de Campinas - UNICAMP & 309 \\
\hline $3^{\circ}$ & Universidade Federal de Minas Gerais - UFMG & 295 \\
\hline $4^{\circ}$ & Universidade Federal do Paraná - UFPR & 233 \\
\hline $5^{\circ}$ & Universidade Federal do Ceará - UFC & 183 \\
\hline $6^{\circ}$ & Universidade Federal do Rio Grande do Sul - UFRGS & 148 \\
\hline $7^{\circ}$ & Universidade Federal da Paraíba - UFPB & 141 \\
\hline $8^{\circ}$ & Universidade Federal de Pelotas - UFPEL & 132 \\
\hline $9^{\circ}$ & Universidade Estadual Paulista Julio de Mesquita Filho - UNESP & 126 \\
\hline $10^{\circ}$ & Universidade Federal do Rio Grande do Norte - UFRN & 119 \\
\hline $55^{\circ}$ & Universidade Federal do Tocantins - UFT & 20 \\
\hline
\end{tabular}

Fonte: Adaptada de INPI (2018)

Conforme mostra a Tabela 5, a instituição de ensino superior com o maior número de depósitos de MU é o Instituto Federal de Educação, Ciência e Tecnologia de Rondônia, seguidos do SENAI e UFMG com respectivamente 18, 17 e 14, quando analisados o período de 2013 a 2017.

Tabela 5 - Ranking das Posições das Instituição de Ensino Superior do Brasil 2013-2017 dos depósitos de MU

\begin{tabular}{|c|c|c|}
\hline Posıção & $\begin{array}{c}\text { RANKING DAS POSIÇÕES DAS INSTITUIÇÃo DE ENSINO SUPERIOR do BRASIL } 2013 \text { - } 2017 \\
\text { DOS DEPÓSITOS DE MU }\end{array}$ & QD \\
\hline $1^{\circ}$ & Instituto Federal de Educação, Ciência e Tecnologia de Rondônia & 18 \\
\hline $2^{\circ}$ & Serviço Nacional de Aprendizagem Industrial - SENAI & 17 \\
\hline $3^{\circ}$ & Universidade Estadual do Oeste do Paraná - UNIOESTE & 14 \\
\hline $4^{\circ}$ & Universidade de São Paulo - USP & 13 \\
\hline $5^{\circ}$ & Universidade Federal do Rio Grande do Sul - UFRGS & 12 \\
\hline $6^{\circ}$ & Universidade do Estado do Rio de Janeiro - UERJ & 9 \\
\hline $7^{\circ}$ & Universidade Estadual Paulista Júlio de Mesquita Filho - UNESP & 9 \\
\hline $8^{\circ}$ & Universidade Tecnológica Federal do Paraná - UTFPR & 9 \\
\hline $9^{\circ}$ & Pontifícia Universidade Católica de Minas Gerais - PUC Minas & 8 \\
\hline $10^{\circ}$ & Universidade Federal de Minas Gerais - UFMG & 8 \\
\hline $25^{\circ}$ & Universidade Federal do Tocantins - UFT & 3 \\
\hline
\end{tabular}

Fonte: Adaptada de INPI (2018) 
Nesse cenário desafiador, a Universidade Federal do Tocantins (UFT) completou, desde a criação do seu Núcleo de Inovação Tecnológica (NIT-UFT) em 2011, até o final de 2018, um total de 32 depósitos de patentes onde. Em um ranking de 123 instituições de ensino superior do Brasil a UFT ficou na $25^{a}$ posição, pode ser considerada uma boa posição, pois estaria apenas 15 depósitos atrás do primeiro colocado, quando analisados no período de 2013 a 2017.

A contribuição percentual dos depósitos de patentes da UFT no estado do Tocantins em 2013 foi de 20\%, em 2014 teve a maior contribuição de 42,86\%, 2015 a menor contribuição de 12,5\% e 2016, 2017 com 33,33\% cada ano. O que reforça que a instituição UFT é referência dos depósitos de PI e MU para o estado do Tocantins.

A UFT contribuiu aproximadamente em média com 5 depósitos por ano o que deixa clara a importância das atividades do NIT da UFT no Tocantins para o desenvolvimento tecnológico no âmbito do estado do Tocantins. A princípio, pode-se dizer, que todos os depósitos de patentes da UFT têm potencial de mercado, ou seja, para a transferência tecnológica podendo contribuir para o Tocantins e para região Norte.

Na Tabela 6, apresenta-se o resumo de todas as patentes que não estão sobre sigilo e que a UFT disponibilizou contendo uma parte da redação de patente do seu depósito. A Tabela 6 mostra todos os processos de depósitos de patentes desde 2013 até 2018 que foram encontrados através do CNPJ da Universidade Federal do Tocantins (UFT) utilizando-se do banco de dados on line de patentes do Instituto Nacional da Propriedade Industrial (INPI). O primeiro depósito da UFT foi realizado em 2013 intitulado: "MÉTODO DE SÍNTESE DE CRIOLITA A PARTIR DE LODO DE ESTAÇÕES DE TRATAMENTO DE ÁGUA", ou seja, trata-se de um novo método no tratamento de água e líquidos para a indústria de alumínio o que marcou um início de futuras e sucessivas produções patentárias. Esse depósito de patente apresentaria uma vantagem de ser um método simples e econômico para os rejeitos das Estações de Tratamento de Águas.

Tabela 6 - Relação dos Depósitos de Patentes da UFT

\begin{tabular}{|c|c|c|}
\hline Processos & $\begin{array}{l}\text { DATA do } \\
\text { DePósito }\end{array}$ & Título \\
\hline BR10 20190027436 & $11 / 02 / 2019$ & Sigilo \\
\hline BR 1020180733087 & $12 / 11 / 2018$ & Sigilo \\
\hline BR 1020180712985 & $16 / 10 / 2018$ & Sigilo \\
\hline BR 1020180685112 & $12 / 09 / 2018$ & Sigilo \\
\hline BR 2020180678766 & 05/09/2018 & Sigilo \\
\hline BR 1020180081276 & 20/04/2018 & Sigilo \\
\hline BR 2020180078408 & $18 / 04 / 2018$ & Sigilo \\
\hline BR 2020170228822 & $24 / 10 / 2017$ & Sigilo \\
\hline BR 1020170212165 & 03/10/2017 & Sigilo \\
\hline BR 1020170209407 & 29/09/2017 & Sigilo \\
\hline BR 1020170145484 & 30/06/2017 & Sigilo \\
\hline BR 1020170145468 & 29/06/2017 & Sigilo \\
\hline BR 1020170087018 & 26/04/2017 & Sigilo \\
\hline
\end{tabular}


BR 1020170073599

$04 / 04 / 2017$

BR $1020160147670 \quad$ 14/06/2016

BR 1020160101530

$28 / 04 / 2016$

BR $1020160088887 \quad 11 / 04 / 2016$

BR $1020160069874 \quad$ 22/03/2016

BR 1020160050065 17/02/2016

BR $1020150307128 \quad$ 27/11/2015

BR 1020150163568 30/06/2015

BR 1020140291954 18/11/2014

BR 1020140291946 17/11/2014

BR 1020140263250 10/10/2014

BR $1020140234470 \quad$ 16/09/2014

BR 1020140181881 02/07/2014

BR 1020140129715 19/02/2014

BR $2020130340770 \quad$ 17/12/2013

BR 1020130337641 20/09/2013

BR 1020130207969 15/08/2013

BR 2020130093217 10/04/2013

BR 1020130040959 14/02/2013
Uso do Óleo Essencial de Morinda Citrifolia Linn (NONI) em Formulação com fins Inseticida e Repelente

Processo para Produção de Monossacarídeos Fermentescíveis a partir de

Quitina e/ou Quitosana por Hidrólise Química e/ou Enzimática e seus usos

Bebida láctea à base de extrato hidrossolúvel de amêndoa de babaçu e seu

Processo de obtenção com cultura probiótica

Maionese com polpa de açaí e o seu respectivo método de processamento

Separação de proteínas do soro de leite bovino com a aplicação do babaçu

Uso de gel de quitosana como coagulante $e$ floculante no tratamento de águas

E efluentes

Gabarito portátil para construção de pingadeiras

Biorreator com cesto poroso para uso em reações com células e enzimas Imobilizadas

Processo de adição de ácido graxo como matériaprima na massa de cerâmica vermelha

Método de extração e processamento de produtos à base de polpa integral de bacaba

Uso da levedura saccharomyces cerevisiae CEPA UFMG 905 como promotor da Redução de micotoxinas em grão

Processo de separação e purificação da a-lactoalbumina e b-lactoglobulina

Por combinação da cromatografia de troca iônica, sistemas aquosos bifásicos

E cromatografia de exclusão molecular

Processo de obtenção de emulsões de glicerina para aplicação de herbicidas

Suporte único para hemoderivados, soluções, medicação e equipamento na Cirurgia cardiovascular

Uso do Óleo Essencial de Siparuma Guianensis Aublet (Negramina). Formulações Com Fins Inseticidas e Repelentes (arquivada)

Processo para obtenção e utilização de pectina, com alto grau de metoxilação De pericarpo do fruto de pequi

Estetoscópio eletrônico piezoelétrico de baixo custo

Método de síntese de criolita a partir de lodo de estações de tratamento de água 
A BR 202013 009321-7, conforme mostra a Tabela 6, é um Modelo de Utilidade (MU) que se refere a um estetoscópio eletrônico de baixo custo, isto é, uma tecnologia da área da saúde; A BR 102013 020796-9, trata-se de uma extração da pectina encontrada no pequi, fruto típico do TO, caracterizada por ser um agente que pode ser utilizado em composições farmacêuticas, cosméticas, alimentícias e químicas, podendo ser utilizada também nas associação à sais e sacarose; A BR 202013 034077-0, é uma PI destinada a cirurgias cardíacas com um suporte com ganchos que irá auxiliar para o procedimento sem a necessidade de um profissional para pegar os instrumentos, isto é, área da saúde; A BR 102014 012971-5, é uma PI destinada no processo de obtenção de emulsões de glicerina para aplicação de herbicidas; A BR 102014 018188-1, é uma PI desenvolvido para separação e purificação das proteínas presentes no soro de leite; A BR 102014 023447-0, é uma PI, que evita a contaminação de grãos e conserva ao mesmo tempo, excelente tecnologia para ser utilizado no agronegócio; A BR 102014 026325-0, é uma PI para extração e processamento de produtos à base de polpa integral de bacaba, desenvolvido para aplicação em fins industriais; A BR 102014 029194-6, é uma PI que utiliza um processo inovador na fabricação de cerâmicas; A BR 1020140029195 4, é uma PI, que serve como biorreator permitindo um maior contato entre os reagentes e o biocatalisador. Por meio de uma rápida análise desses depósitos de patentes, percebe-se que teriam potencial de mercado e poderiam contribuir de alguma forma para o estado, região $e$ até mesmo o país. Entretanto confirmar que um depósito de patente é melhor que outro seria injusto nesse momento, pois, precisariam ser minuciosamente examinados por técnicos do INPI. O potencial inovador de qualquer desses ativos só pode ser mensurado com eficiência na prática utilizando-se inicialmente de um estudo de valoração, por profissionais especializados, e em um segundo momento no mercado por meio de sua comercialização.

Corroborando com esses resultados, Paranhos et al. (2018) afirmam que a apropriação do conhecimento tecnológico gerado pelas universidades é um ponto de debate pois acredita-se que ele serve de freio para uma melhor aproximação universidade-empresa pois as empresas não teriam interesse em financiar e apoiar pesquisas que gerem conhecimentos que poderão ser utilizados por suas concorrentes, dessa forma, as empresas já estabelecidas não estariam enxergando uma vantagem em tecnologias patenteadas por universidades. Entende-se que uma das formas de minorar esse problema seria a criação de incubadoras de empresas por iniciativa da própria universidade com a finalidade de favorecer o empreendedorismo de estudantes, professores e técnicos. De acordo com ANPROTEC (2016), de 1999 a 2004, o número de incubadoras no Brasil quase triplicou passando de 100 a 283 em quase cinco anos. Esses dados mostram o quanto as incubadoras têm sido importantes para a Transferência Tecnológica nas universidades.

\section{Considerações Finais}

Os objetivos do presente estudo foram supridos e obteve-se resultados práticos importantes os quais podemos citar a seguir. Primeiramente, foi possível verificar que o NIT da UFT possui um histórico de experiências ainda incipiente e apresenta baixa qualificação no que se refere ao desenvolvimento de processos e estratégias com vistas à Transferência de Tecnologias. Contudo, há um grupo de docentes fortemente envolvidos ao tema da inovação tecnológica, 
propriedade intelectual, patentes, registros de softwares, criação de novas tecnologias e projetos de Incubadoras de Empresas.

Por outro lado, identificou-se que, mesmo com baixos números de depósitos de patentes, a Universidade Federal do Tocantins (UFT) apresenta um papel de destaque para o Tocantins, pois representou 1/3 do total dos depósitos entre os anos de 2016 e 2017 para este estado, além disso ocupa a terceira colocação no ranking dos depósitos de patentes na região Norte do país. Observou-se que também existe um considerável número de depósitos de Patentes de Invenção (PI) em relação aos depósitos de Patentes de Modelo de Utilidade (MU) o que mostra a boa disposição da UFT para o desenvolvimento de tecnologias disruptivas.

Entretanto, alguns pontos precisariam ser atendidos, como a elaboração e execução de um planejamento estratégico para as ações do NIT da UFT com a firme proposta de que suas atribuições pudessem de fato cumprir os apontamentos da legislação em vigor, bem como revisão e publicação oficial do regimento interno, ao qual ainda está em debate no âmbito da universidade. Para isso, seria necessário um melhor alinhamento do plano estratégico da política de inovação com os interesses emergentes da academia, especialmente dos professores pesquisadores, em consonância aos interesses da iniciativa privada, sob a pena de restringir-se somente ao plano teórico em suas funções precípuas. Sendo assim, o NIT da UFT poderia tomar algumas iniciativas, como: elaborar um plano de negócio e estudo de mercado para cada depósito de patentes, promover um maior número de palestras, apresentações em eventos, previamente organizados, com a finalidade de criar vitrines tecnológicas dos depósitos das patentes produzidas da UFT, aproximando-se cada vez mais das empresas privadas.

De acordo com o regimento interno do NIT-UFT, ele deveria cumprir a função de Agência de Inovação e Difusão Tecnológica, mas isso não ocorre na prática, pois a sua equipe ainda é pequena e parece não haver interesse da instituição no momento na ampliação do seu quadro, até o presente momento da pesquisa. Por outro lado, foi possível perceber que não há uma comunicação eficiente entre o corpo acadêmico da UFT, o qual seria incumbido de produzir novas tecnologias e, consequentemente dar início aos processos de inovação. Ao relacionar os setores tecnológicos dos documentos de patentes da UFT ao perfil da indústria do Estado do Tocantins, observou-se uma boa compatibilidade entre as áreas, onde provavelmente existe a demanda de novas tecnologias.

Com a finalidade de melhorar este cenário, ações poderiam ser criadas para aproximar o conjunto de empresários que compõe a indústria tocantinense. Identificou-se que este seria um ponto importante, pois, o não atendimento deste requisito, poderia fazer com que a universidade produzisse tecnologia que não necessariamente interessaria para indústria regional. Acredita-se que algumas dificuldades independem da gestão interna, pois muitas situações ocorrem devido às contenções orçamentárias do Poder Executivo, ou mesmo devido a uma indefinição de uma política clara de inovação por parte do Estado, que seja democrática e ao mesmo tempo eficiente e, até mesmo devido à baixa qualificação de recursos humanos.

Acredita-se que a implantação do Programa de Mestrado PROFNIT em 2018 na Universidade Federal do Tocantins vem em um momento oportuno e provocará, nos próximos anos, uma melhora sensível no nível de qualificação de recursos humanos para tratar do tema e assim auxiliar a planejar e prospectar parcerias com vistas à Transferência de Tecnologia.

Conclui-se que a universidade está trabalhando e aprendendo com erros e acertos, apesar das necessárias melhorias na estruturação do Núcleo de Inovação, com vistas a traçar estra- 
tégias de investimento de tempo, esforço e recursos orçamentários para redirecionar o foco para a Transferência de Tecnologia como meta principal da gestão do NIT. Salienta-se que os resultados deste trabalho podem servir de base para futuros estudos ou até mesmo para embasar o planejamento de futuras ações estratégicas por parte dos gestores. Este estudo permitiu perceber que a estruturação do Mestrado PROFNIT se coloca em um momento onde um maior número de docentes procuram direcionar seus esforços para o desenvolvimento de projetos de inovação, principalmente sob a perspectiva de apropriação tecnológica por meio de patentes e, dessa forma, não somente o NIT será contemplado com novas ações, mas o movimento caracterizado por um desenvolvimento de novas incubadoras será cada vez mais intenso, devido principalmente a experiência já acumulada e pela crescente qualificação de recursos humanos.

\section{Referências}

AUDY, J. L. N.; MOROSINI, M. C. (org.). Innovation and Interdisciplinarity at the university. Porto Alegre: PUCRS/FINEP, 2007.

BOZEMAN, B. Technology transfer and public policy: a review of research and theory. Research Policy, [S.l.], v. 29, p. 627-655, 2000.

CARVALHO, S. M. S et al. Empreendedorismo, tecnologia e inovação: temas contemporâneos na gestão da Universidade de Brasília. Cadernos de Prospecção, Salvador, v. 10, n. 4, p. 626-638, out. - dez., 2017.

DE BENEDICTO, Samuel Carvalho. Apropriação da Inovação em agrotecnologias: Estudo Multicaso em Universidade Brasileiras. Lavras: UFLA, 2011.

DIAS, A.; PORTO, G. S. Gestão de transferência de tecnologia na inova Unicamp. Revista de Administração Contemporânea, [S.l.], v. 17, n. 3, p. 263-284, 2013. Disponível em: http://www. scielo.br/pdf/rac/v17n3/a02v17n3.pdf. Acesso em: 25 fev. 2019.

ETZKOWITZ, H. Hélice Tríplice: Universidade-Indústria-Governo: Inovação em Movimento. Porto Alegre: EDIPUCRS, 2009. 214 p.

FIETO. Federação das Indústrias do Tocantins. Sondagem Industrial $4^{\circ}$ trimestre de 2018. Disponível em: http://www.fieto.com.br/DownloadArquivo.aspx?c=a7e173c2-b00b-45cc-b2957ac5303a850a. Acesso em: 27 fev. 2019.

FREEMAN, Chris. The economics of innovation. Aldershot: Edward Elgar Publishing, 1990.

GONÇALVES, L. C. Manual de direito industrial: Propriedade Industrial e concorrência desleal. 6. ed. Coimbra: Almedina, 2015.

GRUPP, Hariolf. Foundations of the economics of innovation. Theory, measurement and practice. Massachusetts: Edward Elgar Publishing, 1998.

INPI. Instituto Nacional da Propriedade Industrial. Estatística. [2018]. Disponível em: http://www. inpi.gov.br/sobre/estatisticas. Acesso em: 25 nov. 2018.

KANNEBLEY JÚNIOR, S.; SHIMADA, E.; DE NEGRI, F. Efetividade da lei do bem no estímulo aos dispêndios em P\&D: uma análise com dados em painel. Pesquisa e Planejamento Econômico, [S.l.], v. 46, n. 3, 2016. 
KAYMAZ, K.; YASIN ERYIĞIT, K. Y. Determining factors hindering university-industry collaboration: an analysis from the perspective of academicians in the context of entrepreneurial science paradigm. International Journal of Social Inquiry, [S.l.], v. 4, n. 1, p. 185-213, 2011. Disponível em: http:// www.acarindex.com/dosyalar/makale/acarindex-1423904053.pdf. Acesso em: 18 fev. 2019.

LUCENA, R. M.; SPROESSER, R. L. Análise da gestão de licenciamento de patentes: estudo multicasos de instituições federais de ensino superior. Revista de Administração e Inovação, [S.l.], v. 12, n. 3, p. 28-55, 2015. Disponível em: http://dx.doi.org/10.11606/rai.v12i3.100934. Acesso em: 28 fev. 2019.

PARANHOS, J.; HASENCLEVER L.; PERIN, F. S. Abordagens teóricas sobre o relacionamento entre empresas e universidades e o cenário brasileiro. Revista Econômica, Niterói, [S.l.], v. 20, n. 1, p. 9, 29. Junho de 2018. Disponível em: http://www.revistaeconomica.uff.br/index.php/ revistaeconomica/article/view/387. Acesso em: 18 fev. 2019.

PROEX UFT. Pró-Reitoria de Extensão, Cultura e Assuntos Comunitários da Universidade Federal do Tocantins. Incubadora de Projetos Pedagógicos e Inovação para Escolas de Ensino Fundamental e Médio. 2018. Disponível em: https://ww2.uft.edu.br/index.php/proex/programase-projetos/16373-incubadora-de-projetos-pedagogicos-e-inovacao-para-escolas-de-ensino fundamental-e-médio. Acesso em: 3 dez. 2018.

\section{PROFNIT. Programa de Pós-Graduação em Propriedade Intelectual e Transferência de} Tecnologia para a Inovação. 2018. Disponível em: http://www.profnit.org.br/pt/sample-page/. Acesso em: 3 dez. 2018.

PRONDANOV, C. C.; FREITAS, E. C. Metodologia do Trabalho Científico: métodos e técnicas da pesquisa e do Trabalho Acadêmico. Rio Grande do Sul: Freevale, 2013. 277p.

ROSA, R. A.; FREGA, J. R. Intervenientes do Processo de Transferência Tecnológica em uma Universidade Pública. Rev. adm. contemp., Curitiba, v. 21, n. 4, p. 435-457, jul. 2017. Disponível em: http:/www.scielo.br/scielo.php?script=sci_arttext\&pid=S141565552017000400435\&lng=en\&n rm =iso. Acesso em: 19 fev. 2019.

REIS, D. A.; GOMES, I. M. Capital Humano, Intensidade da Inovação e crescimento econômico no Brasil. 8th International Symposium on Technological Innovation, [S.l], p. 44- 55, 2017.

SANTOS, M. E. R.; SOLLEIRO, J. L. Relações universidade-empresa no Brasil: diagnóstico e perspectivas. Innovation and Entrepreneurialism in the Universit. AUDY, Jorge Luis Nicolas. Porto Alegre: EDIPUCRS, 2006. Capítulo 12.

SCHUMPETER, J. Teoria do Desenvolvimento Econômico, uma investigação sobre lucro, capital, crédito, juros e o Ciclo Económico. São Paulo: Nova Cultural Ltda., 1997.

SEVERINO, Antônio Joaquim. Metodologia do Trabalho Científico. São Paulo: Cortez, 2010.

STEVENS, A.; TONEGUZZO, F; BOSTROM, D. AUTM U.S. licensing survey: FY 2004 [Survey summary]. Association of University Technology Managers. 2005. Disponível em: http://www. immagic.com/eLibrary/ARCHIVES/GENERAL/AUTM_US/A051216.pdf. Acesso em: 21 nov. 2018.

SUZIGAN, W.; ALBUQUERQUE, E. M.; CARIO, S. A. F. Em busca da inovação: interação universidade-empresa no Brasil. Belo Horizonte: Autêntica Editora, 2011.

NIT-UFT. Núcleo de Inovação Tecnológica da Universidade Federal do Tocantins. 2018. Portfólio de patentes. Disponível em: http://ww2.uft.edu.br/index.php/nit/vitrine-tecnologica/ portifolio-de-patentes. Acesso em: $3 \mathrm{dez} .2018$. 
UFT - UNIVERSIDADE FEDERAL DO TOCANTINS. Inscrições para Incubadora de Empresas de Biotecnologia (Habite) são prorrogadas. 2016. Disponível em: https://ww2.uft.edu.br/index. php/ultimas-noticias/17142-gurupi-inscricoes-para-incubadora-de-empresas-de-biotecnologia-habitesao-prorrogadas. Acesso em: 3 dez. 2018.

UFT - UNIVERSIDADE FEDERAL DO TOCANTINS. Incubadora de Empresas. 2018. Disponível em: https://ww2.uft.edu.br/index.php/proex/programas-e-projetos/16067-incubadora-de-empresas. Acesso em: 3 dez. 2018.

UFT - UNIVERSIDADE FEDERAL DO TOCANTINS. 2014. Disponível em: https://ww2.uft.edu.br/ index.php/en/ultimas-noticias/13420-incubadora-social-de-empresas-seleciona-tres-iniciativas. Acesso em: 3 dez. 2018.

TEIXEIRA, A. A. C. Excesso de Incentivos à Inovação na Presença de Consumidores Sofisticados: um Modelo de Progresso Tecnológico Endógeno com Capital Humano. Estudos Econômicos, [S.l.], v. 37, n. 3, 2007.

\section{Sobre os Autores}

\section{Marco Antônio Baleeiro Alves}

E-mail: baleeiro@uft.edu.br Mestre em Agroenergia pela Universidade Federal do Tocantins (UFT).

Endereço profissional: Universidade Federal do Tocantins (UFT), Campus Universitário de Palmas. Quadra 109, norte. Av. NS 15 ALCNO 14, Bloco 1, Sala 18. Plano Diretor Norte, Palmas, TO. CEP: 77001-090.

\section{Gabriel Machado Santos}

E-mail: gabrielms11@gmail.com

Especialista em Gestão Estratégica da Inovação e Política de Ciência e Tecnologia (UFT).

Endereço profissional: Universidade Federal do Tocantins (UFT), Campus Universitário de Palmas. Quadra 109, norte. Av. NS 15 ALCNO 14, Bloco 1, Sala 18, Plano Diretor Norte, Palmas, TO. CEP: 77001-090.

\section{Marcos Antônio Dozza}

E-mail:marcosdozza@uft.edu.br

Mestre em Administração Universidade do Estado de Santa Catarina (UESC).

Endereço profissional: Universidade Federal do Tocantins (UFT), Campus Universitário de Palmas. Quadra 109, norte. Av. NS 15 ALCNO 14, Bloco 1, Sala 18, Plano Diretor Norte, Palmas, TO. CEP: 77001-090.

\section{Francisco Gilson Rebouças Pôrto Júnior}

E-mail: gilsonporto@uft.edu.br

Doutor, com estudos de pós-doc na Universidade de Coimbra e na Universidade de Cadiz.

Endereço profissional: Universidade Federal do Tocantins (UFT), Campus Universitário de Palmas. Quadra 109, norte. Av. NS 15 ALCNO 14, Bloco 1, Sala 18, Plano Diretor Norte, Palmas, TO. CEP: 77001-090. 